\title{
ENSAIO BIOMECÂNICO DE FADIGA EM IMPLANTES DENTÁRIOS NITRETADOS A PLASMA EM CÁTODO OCO
}

\author{
Karilany Dantas Coutinho
}

Universidade Federal do Rio Grande do Norte, Departamento de Engenharia

Biomédica, Campus Universitário, Lagoa Nova, Natal, RN, Brasil. CEP: 59072-970.

karilany@ufrnet.br

Paulo Victor de Azevedo Guerra

Universidade Federal do Rio Grande do Norte, Departamento de Engenharia

Biomédica, Lagoa Nova, Natal, RN, Brasil. CEP: 59072-970.

paulovictorguerra@gmail.com

\section{Matheus André Coutinho Ferreira}

Universidade Federal do Rio Grande do Norte, Escola de Ciência e Tecnologia, Campus

Universitário, Lagoa Nova, Natal, RN, Brasil. CEP: 59072-970. matheuscoutinho10@hotmail.com

\section{Ricardo Alexsandro de Medeiros Valentim}

Universidade Federal do Rio Grande do Norte, Departamento de Engenharia

Biomédica, Campus Universitário, Lagoa Nova, Natal, RN, Brasil. CEP: 59072-970. ricardo.valentim@ufrnet.br

Custódio Leopoldino de Brito Guerra Neto

Universidade Federal do Rio Grande do Norte, Departamento de Engenharia

Biomédica, Campus Universitário, Lagoa Nova, Natal, RN, Brasil. CEP: 59072-970. custodioguerra@yahoo.com.br

\section{João Carlos Arantes Costa Júnior}

Universidade Federal do Rio Grande do Norte, Departamento de Engenharia Mecânica,

Campus Universitário, Lagoa Nova, Natal, RN, Brasil. CEP: 59072-970.

arantes_jr@yahoo.com.br

\begin{abstract}
RESUMO
Biomecânica é o estudo do movimento e do efeito das forças sobre os sistemas biológicos e em organismos vivos. Testes biomecânicos podem ser realizados com várias finalidades: para testar ou comparar diferentes métodos de fixação, a resistência de diferentes tipos de componentes, dentre eles, os implantes, além disso, estudar a distribuição das tensões no osso e o deslocamento, após aplicação de determinado método de estabilização de fraturas. Nesse trabalho foi realizado um ensaio biomecânico de fadiga com o objetivo de avaliar a eficácia do tratamento superficial aplicado ao implante nitretado a plasma em cátodo oco. A partir deste ensaio biomecânico de fadiga foi possível analisar: a força de escoamento, a força de ruptura do implante, a localização da falha e o momento fletor máximo para a força máxima de resistência à ruptura. Os resultados mostraram-se satisfatórios.
\end{abstract}

\section{PALAVRAS-CHAVE:}

Biomecânica, Ensaio de Fadiga, Implante Dentário. 


\title{
BIOMECHANICAL FATIGUE TEST IN DENTAL IMPLANTS PLASMA NITRIDED IN A HOLLOW CATHODE
}

\begin{abstract}
Biomechanics is the study of movement and the effect of loads on biological systems and living organisms. Biomechanical tests can be performed for several purposes: to test or to compare different methods of fixing the strength of different types of components, including, implants, further consider the stress distribution in the bone and the displacement after a certain application method of stabilizing fractures. In this paper we present a biomechanical test fatigue in order to assess the effectiveness of surface treatment applied to the implant in plasma nitrided the hollow cathode. From this biomechanical endurance test were used to analyze: the yield strength, the tensile strength of the implant, the location of the fault and the maximum bending moment to the maximum force of tensile strength. The results were satisfactory.
\end{abstract}

\section{KEYWORDS:}

Biomechanics, fatigue test, Dental Implants. 


\section{ENSAIO BIOMECÂNICO DE FADIGA EM IMPLANTES DENTÁRIOS NITRETADOS A PLASMA EM CÁTODO OCO}

\section{INTRODUÇÃO}

Ainda que o método de implantes já tenha se consagrado como uma possível possibilidade para a restauração das perdas dentais, [1], a eventual confirmação de que determinadas superfícies possibilitam o maior e o mais rápido contato ósseo, na fase de cicatrização, e durabilidade, quanto em sua funcionalidade, poderá certamente contribuir para aperfeiçoar o procedimento, ver [2].

A necessidade de se definir uma superfície em implantes metálicos compatíveis com uma boa resposta óssea é imperativa na pesquisa básica de implantes, especialmente na busca de soluções para área de baixa densidade óssea, [3]. O implante, uma vez em contato com o meio biológico, é caracterizado por mudanças dinâmicas em suas propriedades superficiais, envolvendo uma cascata de reações que ocorre entre o meio biológico e o biomaterial, formando assim um "filme de condicionamento" que modula as respostas celulares do hospedeiro, [4].

$\mathrm{Na}$ busca por superfícies que supram a necessidade de se obter uma rápida osseointegração, diversas pesquisas são desenvolvidas, com o objetivo de modificar tais superfícies, por meio de métodos mecânicos, químicos e físicos de tratamento de superfície, obtendo-se assim, diversos níveis de texturas, ver [5], [6] e [7]. Nesse sentido, busca-se nesta pesquisa uma superfície que atenda a essa necessidade. Selecionou-se, desta forma, o processo de nitretação em plasma pelas excelentes propriedades mecânicas, estabilidade química e biocompatibilidade, [8], quando aplicada ao titânio. Seu uso para implantes de quadril, joelho, ombro e tornozelo tem levado a uma crescente resistência à abrasão e colonização bacteriana reduzida, comparada a outras superfícies de implantes clinicamente utilizadas, [9], [10] e [11]. Entretanto, uma limitação do uso da nitretação em implantes dentais está na alta temperatura do processo, entre 700 e $800^{\circ} \mathrm{C}$ podendo causar distorções no implante devido a sua geometria e precisão dimensional, [12]. Uma alternativa para solucionar esse problema é o tratamento na configuração de Cátodo Oco. Este método consiste em nitretar a peça numa atmosfera altamente ionizada. Uma alta densidade de íons significará maior bombardeamento na superfície, ocasionando uma alta incidência energética.

Além da textura superficial, a engenharia odontológica vem mostrando resultados de novas técnicas e novos materiais para desenvolvimento de implantes cada vez mais semelhantes à dentição natural, tanto estética quanto biomecanicamente, proporcionando conforto e equilíbrio aos pacientes desdentados.

A biomecânica relacionada à otimização desses implantes e componentes protéticos pode ter um papel decisivo para o sucesso, podendo estes ter a capacidade de melhorar distribuição de forças, diminuindo então, a carga sobre o osso circunjacente. Juntamente com esses fatores, uma oclusão equilibrada é foco dos profissionais da área, pois, uma força oclusal excessiva, principalmente durante a mastigação, pode levar a altos níveis de tensão ao osso e ao implante, trazendo possíveis complicações ao sistema prótese /implante /periimplante como: reabsorções ósseas, desaparafusamentos, deformidades e/ou fraturas de tais componentes e implantes, [13].

Nesse trabalho foi realizado um ensaio biomecânico de fadiga com o objetivo de avaliar a eficácia do tratamento superficial aplicado ao implante nitretado a plasma em 
cátodo oco. A partir deste ensaio biomecânico de fadiga foi possível analisar: a força de escoamento, a força de ruptura do implante, a localização da falha e o momento fletor máximo para a força máxima de resistência à ruptura.

\section{MATERIAIS E MÉTODOS}

\section{Ensaio Biomecânico de Fadiga em Flexão em Implantes Dentários}

O ensaio biomecânico de fadiga em flexão deste trabalho foi executado conforme especificado pela norma ABNT NBR ISO 14801 [14] e realizado por um laboratório devidamente acreditado pela CGCRE/INMETRO de acordo com a norma ABNT NBR ISO/IEC 17025.

Segundo norma técnica específica para o ensaio, realizou-se inicialmente um ensaio estático e posteriormente, o ensaio dinâmico de fadiga.

Para o ensaio estático, utilizou-se a máquina SHIMADZU AG-IS/I/IC/EZ Graph $100 \mathrm{kN}$. O ensaio foi realizado com uma amostra (implantes dentários, hexagonal externo com $13 \mathrm{~mm}$ de comprimento e $3,75 \mathrm{~mm}$ de diâmetro, com tratamento superficial) sendo a mesma fixada a um bloco fabricado em poliacetal, a fim de identificação da carga de referência para execução de um posterior ensaio de fadiga em flexão.

A Tabela 1 mostra os parâmetros utilizados durante o ensaio estático biomecânico.

Tabela 1: Parâmetros utilizados no Ensaio Estático.

\begin{tabular}{|c|c|}
\hline Velocidade de Ensaio (mm/min) & 5 \\
\hline I & $12,3 \mathrm{~mm} *$ \\
\hline Meio & Temperatura Ambiente \\
\hline Amostras Ensaiadas & 01 \\
\hline Material Bloco Base & Poliacetal** \\
\hline Equipamento de Ensaio & Shimadzu AG-IS/I/IC/EZGraph 100kN \\
\hline \multicolumn{2}{|c|}{$\begin{array}{l}\text { * Valor utilizado devido à altura do pilar (considerado exposição de } 3 \mathrm{~mm} \text { do implante, valor equivalente } \\
\text { a absorção óssea, segundo ABNT NBR ISO 14801). } \\
\text { ** Poliacetal (POM), também conhecido como Acetal, é um polímero proveniente do formaldeído, um } \\
\text { plástico resistente, descoberto em } 1956 .\end{array}$} \\
\hline
\end{tabular}

O ensaio dinâmico de fadiga, realizado no equipamento BRASVALVULAS BME 5 120/AT, foi executado com 12 (doze) amostras fixadas a um bloco confeccionado também do material poliacetal.

A intensão da realização do referido ensaio mecânico foi avaliar a eficácia do tratamento superficial aplicado ao implante em estudo, nitretação a plasma em cátodo oco. A partir deste ensaio biomecânico de fadiga foi possível analisar: a força de escoamento, a força de ruptura do implante, a localização da falha e o momento fletor máximo para a força máxima de resistência à ruptura.

A Figura 1 mostra a configuração do sistema para o ensaio do componente protético durante o ensaio biomecânico, conforme especificado na norma ABNT NBR ISO 14801:2012. 


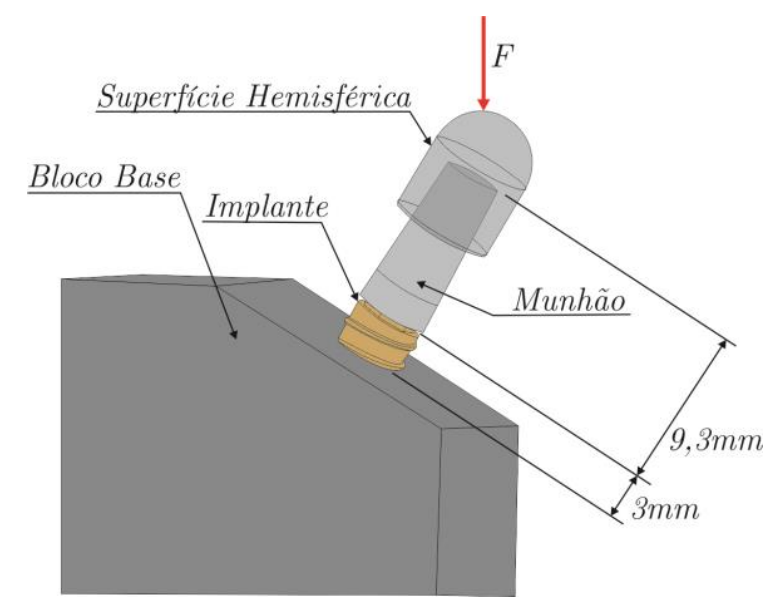

Figura 1: Configuração do sistema para ensaio de componente protético, ABNT NBR ISO 14801:2012.

A Tabela 2 mostra os parâmetros utilizados no ensaio biomecânico de fadiga dos implantes nitretados a plasma em cátodo oco.

Tabela 2: Parâmetros utilizados no Ensaio de Fadiga.

\begin{tabular}{l|l}
\hline Força de Frequência & $422,25 \mathrm{~N}$ \\
\hline Frequência & $15 \mathrm{~Hz}$ \\
\hline Razão entre Carregamentos & 0,1 \\
\hline Número de Ciclos & $5 \times 10^{6}$ Ciclos \\
\hline Material Bloco Base & Poliacetal \\
\hline Meio & Temperatura Ambiente \\
\hline Equipamento de Ensaio & Brasvalvulas BME 5 120/AT \\
\hline
\end{tabular}

A Figura 2 representa a configuração utilizada no ensaio biomecânico para a aplicação do carregamento.

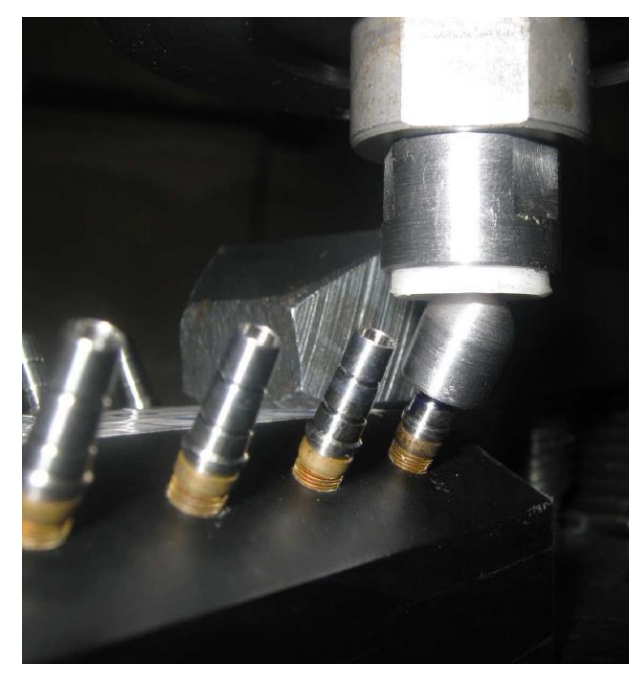

Figura 2: Configuração utilizada no ensaio para aplicação da carga.

Para realizar o ensaio, o implante foi fixado de forma que seu eixo central fizesse um ângulo de $30^{\circ}$ em relação direção do carregamento do equipamento do ensaio. 
Uma força de carregamento posicionada sobre o eixo longitudinal central do implante, de $\mathrm{F}=422,25 \mathrm{~N}$ foi aplicada através de um componente de carregamento resistente à deformação com uma superfície de contato hemisférica para a transferência de carga, colocado sobre a extremidade livre da parte da conexão. A força de carregamento foi aplicada à superfície de carregamento hemisférica por um dispositivo de força com uma superfície plana normal à direção de carregamento da máquina.

A cada ensaio, as superfícies de carregamento hemisférico e de carregamento do dispositivo foram examinadas visualmente, a fim de assegurar que não ocorreu deformação permanente. A parte de ancoragem óssea do corpo de prova foi fixada em um dispositivo de fixação rígida confeccionado de Poliacetal,

Tabela 3, com módulo de elasticidade $3 G P A$, valor este próximo ao módulo de elasticidade do osso. O dispositivo foi projetado para não deformar o corpo de prova e fixado ao corpo de prova a uma distância de $3,0 \mathrm{~mm}$, a partir do nível ósseo.

Tabela 3: Propriedades Mecânicas do Poliacetal.

\begin{tabular}{l|l}
\hline Densidade & $1410 \mathrm{~kg} / \mathrm{m}^{3}$ \\
\hline Tensão de Escoamento a Tração & $66 \mathrm{MPa}$ \\
\hline Tensão de Ruptura a Compressão & $100 \mathrm{MPa}$ \\
\hline Tensão de Ruptura a Flexão & $95 \mathrm{MPa}$ \\
\hline Módulo de Elasticidade & $3000 \mathrm{MPa}$ \\
\hline
\end{tabular}

Fonte: www.matweb.com

A dimensão do braço de alavanca é definida como:

$$
y_{b}=I \operatorname{sen} 30^{\circ}
$$

$$
y_{b}=I \operatorname{sen} 30^{\circ}
$$

Com $I=12,3 \mathrm{~mm}$, tem-se $y_{b}=6,15 \mathrm{~mm}$. O momento fletor correspondente a 2,59 Nm fora definido pela expressão:

$$
M=y_{b} \mathrm{~F}
$$

Quanto ao ambiente do ensaio o mesmo foi realizado em ambiente fechado a uma temperatura de $20^{\circ} \mathrm{C}$.

\section{RESULTADOS E DISCUSSÕES}

Em teste de fadiga, realizado conforme norma ABNT NBR ISO 14801:2007 que regulamenta a aprovação dos produtos na certificação FDA (U.S. Food and Drug Administration), o sistema de implante Hexágono Externo da empresa DENTOFLEX ${ }^{\circledR}$ Sistema de Implantes com tratamento superficial Nitretação a Plasma em Cátodo Oco, não apresentou sinal de falha após 5 milhões de ciclos, sob frequência de $15 \mathrm{~Hz}$, Carga de $84,46 \mathrm{~N}$ e Momento Fletor Máximo de $0.52 \mathrm{Nm}$.

A Tabela 4 resume os resultados obtidos no ensaio estático.

Tabela 4: Resultado do Ensaio Estático. 


\begin{tabular}{l|l|l|l|l}
\hline Amostra & $\begin{array}{l}\text { Força de } \\
\text { Escoamento }(\mathrm{N})\end{array}$ & $\begin{array}{l}\text { Momento no } \\
\text { Escoamento } \\
(\mathrm{Nm})\end{array}$ & $\begin{array}{l}\text { Força Máxima } \\
(\mathrm{N})\end{array}$ & $\begin{array}{l}\text { Momento } \\
\text { Máximo }(\mathrm{Nm})\end{array}$ \\
\hline $01 \mathrm{E}$ & 173,12 & 1,06 & 442,25 & 2,59 \\
\hline
\end{tabular}

A Figura 3 apresenta a curva obtida no ensaio de fadiga, Momento Máximo versus Número de Ciclos.

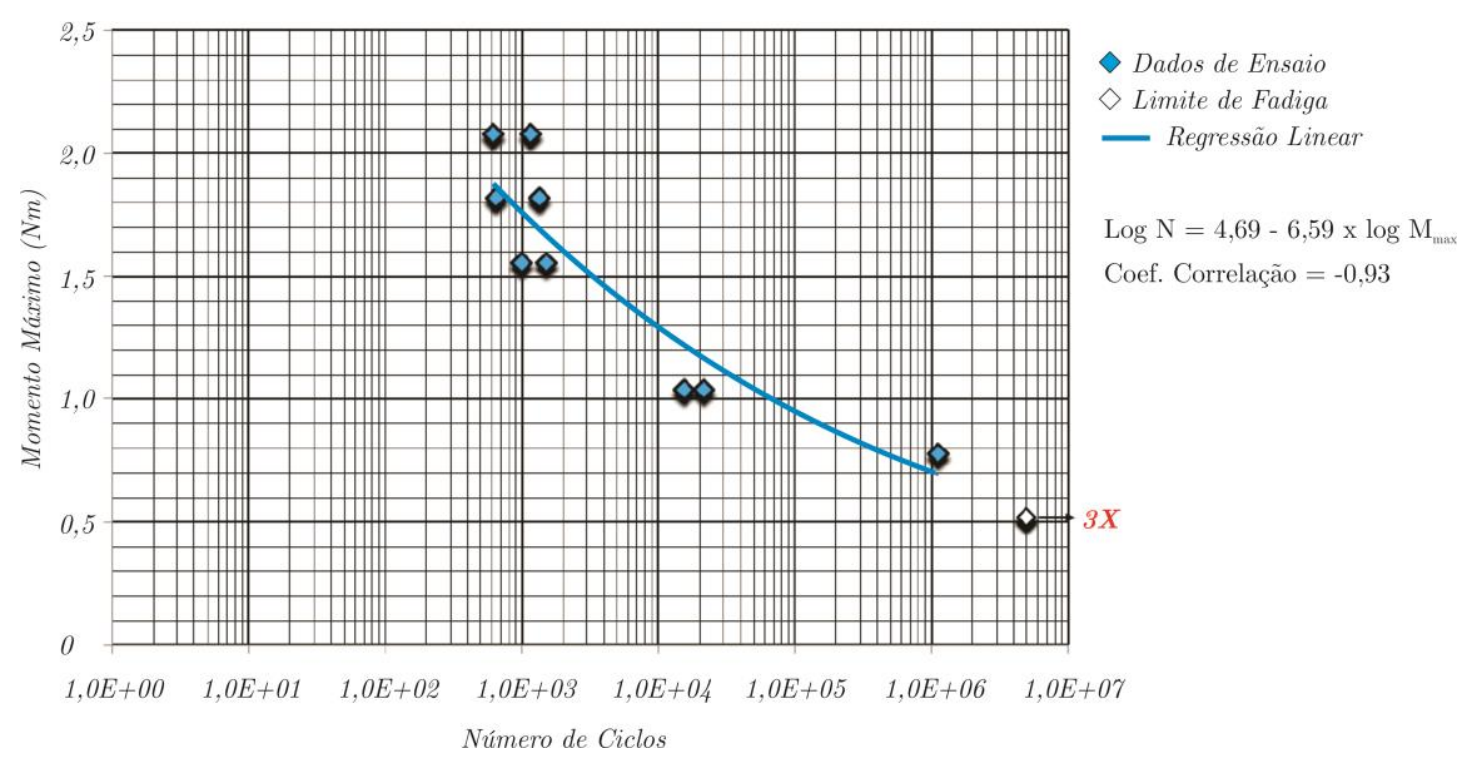

Figura 3: Curva Obtida no Ensaio de Fadiga. Configuração Utilizada no Ensaio de Fadiga para os Corpos de Prova.
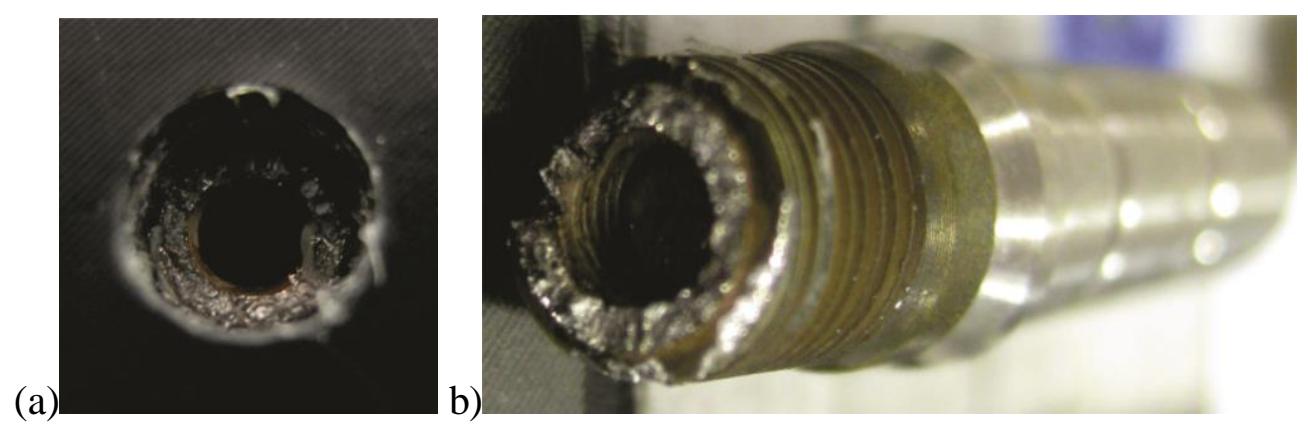

Figura 4: Detalhe do Aspecto das Fraturas.

A Nitretação a Plasma é um processo que eleva a dureza superficial, resultado este mostrado no ensaio de microscopia e confirmado pela análise de microdureza do material. $\mathrm{O}$ aumento da dureza diminui a ductilidade e a capacidade do material absorver energia, tornando-o mais frágil, diminuindo assim o limite de fadiga em relação ao limite de fadiga do material sem tratamento.

\section{CONCLUSÃO}


Baseado no que foi proposto e realizado pela avaliação do desempenho das amostras nitretadas em plasma:

- O processo de nitretação a plasmas adotado na pesquisa aumentou da dureza do material.

- No ensaio biomecânico de fadiga, o implante tratado não apresentou sinal de falha, após 5 milhões de ciclos, a uma carga máxima de fadiga de 84,46N.

- A força máxima de escoamento foi de $173,12 \mathrm{~N}$;

- A falha localizou-se na fixação implante/bloco base.

- O momento fletor máximo para a força máxima de resistência à ruptura de $442,25 \mathrm{~N}$ foi de $2,59 \mathrm{Nm}$.

\section{AGRADECIMENTOS}

Ao LAIS - Laboratório de Inovação Tecnológica em Saúde da Universidade Federal do Rio Grande do Norte.

\section{REFERÊNCIAS}

[1] WENnERBERG, A.; ALBREKTSSON, T. Current Challenges in Successful Rehabilitation with Oral Implants. J. Oral Rehabil. 38(4), p. 286-294, 2011.

[2] OLIVARES-NAVARRETE, R. et al. Osteoblast Maturation and New Bone Formation in Response to Titanium Implant Surface Features and Reduced With Age. J Bone Miner Res. 27(8), p.1773-1783, 2012.

[3] KLEIN, M. O. et al. Submicron Scale-Structured Hydrophilic Titanium Surfaces Promote Early Osteogenic Gene Response for Cell Adhesion and Cell Differentiation. Clin Implant Dent Rel Res., In press. doi: 10.1111/j.17088208.2011.00339, 2011.

[4] STADLINGER, B. et al. Surface-Conditioned Dental Implants: An Animal Study on Bone Formation. J Clin Periodontol 36(10), p. 882-91, 2009.

[5] XUANYONG L.; PAUL K. C.; CHUANXIAN D. Surface Modification of Titanium, Titanium Alloys, and Related Materials for Biomedical Applications. Materials Science and Engineering: R: Report 47 (3-4), p. 49-121, 2004.

[6] SILVA, M. A. M. et al. Surface Modification of Ti Implants by Plasma Oxidation in Hollow Cathode Discharge. Surface \& Coatings Technology 20 (8), p. 612- 620, 2006.

[7] SILVA, M. A. M. et al. Influence of Topography on Plasma Treated Titanium Surface Wettability. Surface \& Coatings Technology, 2013

[8] CHO S., PARK K. The Removal Torque of Titanium Screw Inserted in Rabbit Tibia Treated by dual Acid Etching. Biomaterials 24 (20), p. 3611-3617, 2003

[9] ALVES JR, C. et al. Nitriding of Titanium Disks and Industrial Dental Implants using Hollow Cathode Discharge. Surface and Coatings Technology, 194 (2), p. 196-202, 2005.

[10] SÁ, J. C. et al. Influence of Argon Ion Bombardment of Titanium Surfaces on the Cell Behavior. Surface \& Coatings Technology 203, p. 1765-70, 2009

[11] COELHO, P. G. et al. Argon-Based Atmospheric Pressure Plasma Enhances Early Bone Response to Rough Titanium Surfaces. J Biomed Mater Res. 100 (7), p. 1901-1906, 2012. 
[12] MISHRA, S.C et al. , B. J. Mater. Process. Technol. 132 (2003) 143.

[13] SILVA, E. F. et al. Influência do Tipo de Hexágono e do Diâmetro do implante Osseointegrado na Distribuição de Estresse. Implant News 4 (5), p. 549-54, 2007.

[14] ASSOCIAÇÃO BRASILEIRA DE NORMAS TÉCNICAS, ABNT NBR ISO 14801, Odontologia - Implantes - Ensaio dinâmico de fadiga para implantes odontológicos endósseos, Rio de Janeiro, 2012. 